\title{
Climate change effect on storm drainage networks by storm water management model
}

\author{
Waqed Hammed Hassan ${ }^{\dagger}$, Basim Khalil Nile, Batul Abdullah Al-Masody \\ Department of Civil Engineering, Faculty of Engineering, University of Kerbala, Karbala 56001, Iraq
}

\begin{abstract}
One of the big problems facing municipalities is the management and control of urban flooding where urban drainage systems are under growing pressure due to increases in urbanization, population and changes in the climate. Urban flooding causes environmental and infrastructure damage, especially to roads, this damage increasing maintenance costs. The aim of the present study is to develop a decision support tool to identify the performance of storm networks to address future risks associated with climate change in the Middle East region and specifically, illegal sewer connections in the storm networks of Karbala city, Iraq. The storm water management model has been used to simulate Karbala's storm drainage network using continuous hourly rainfall intensity data from 2008 to 2016. The results indicate that the system is sufficient as designed before consideration of extra sewage due to an illegal sewer connection. Due to climate changes in recent years, rainfall intensity has increased reaching $33.54 \mathrm{~mm} / \mathrm{h}$, this change led to flooding in $47 \%$ of manholes. Illegal sewage will increase flooding in the storm system at this rainfall intensity from between $39 \%$ to $52 \%$.
\end{abstract}

Keywords: Al-Eskari quarter, Climate change, Flooding, Karbala, Storm drainage network, SWMM

\section{Introduction}

There is a long history of the use of drainage systems as far back as the early third millennium B.C. The study of functional technological solutions to water transport problems therefore has a long history, having its roots in ancient times, beginning with a combination of technology with philosophy and science which first appeared in Mesopotamia, Egypt, Hellas, China and India [1]. Interest in these systems is because of the need to dispose of rain water and sewage and to control disease and pollution. At present, storm drainage infrastructures comprise manholes, pipes, gullies and pump stations, these systems usually designed based on historical rainfall data while considering changes in climate that may occur during the expected life of the system. However, if the effects of climate change have been underestimated due to, for example, urbanization, the system will not function to a satisfactory level and increase the probability of urban flooding.

Global warming affects the water cycle, causing a significant rise in temperature and sea levels all over the globe. This increase also causes an increase in rainfall intensity and frequency [2].
In light of this, potential evapotranspiration $\left(\mathrm{ET}_{\mathrm{o}}\right)$ under different types of climate including semiarid, arid, Mediterranean and very humid, has been examined using monthly meteorological data collected over 50 years (1961-2010) in 18 regions of Iran. The results indicate an increase in temperature (mean, maximum and minimum) and a decrease in minimum relative humidity and that signifies a change in climate in most regions of Iran [3]. In addition to climate change, increases in urbanization have an impact by increasing flood discharge where there are changes in surface runoff patterns due to changes in land use.

Records over three periods of time (5, 10 and 49 years) were supplied by Mashhad, Kermanshah, Babolsar and Ahvaz stations and used to evaluate the efficacy of the quantity of recorded data which is used to make monthly rainfall forecasts. The results of the calibration of time series models that forecast rainfall in the future indicate that in semi-arid and temperate climates, 60 observation data points are needed to forecast rainfall. The accuracy of time series models improves with increasing quantities of observation data from humid and arid climates [4].

The Anisotropic effects of natural and man-modified environ-
This is an Open Access article distributed under the terms of the Creative Commons Attribution Non-Commercial License (http://creativecommons.org/licenses/by-nc/3.0/) which permits unrestricted non-commercial use, distribution, and reproduction in any medium, provided the original work is properly cited.

Copyright (C) 2017 Korean Society of Environmental Engineers
Received March 22, 2017 Accepted May 30, 2017

${ }^{\dagger}$ Corresponding author

Email: Waqed2005@yahoo.com

Tel: +964-7801146150

ORCID: 0000-0002-2351-2151 
ments on shallow flood flows and free-surface flow has been studied using subgrid modeling techniques [2-d shallow water models] in Iran. The results shown that anisotropy formed a key role in shallow flows patterns [5]. Estimations of the ratio of irrigation to cultivated land area in Africa and Americas using studies of agricultural water management was developed by Valipour [6] and Valipour [7], respectively.

Urban flooding issues have become easier to analysis and manage due to the development of computer technology and different types of models used in different locations to simulate rainfall-runoff. These include storm water management model (SWMM), MIKE SWMM, and XPSWMM [8], ILLUDAS, [9] and MOUSE [10].

Hsu et al. [11] employed SWMM to examine and measure flooding from the storm drainage network in Taipei, Taiwan, the results helping authorities deal with flooding problems. A similar simulation of the storm drainage system in South Bronx, New York City using SWMM was carried out by Sands et al. [12]. Two simulations were carried out, the first to model the distribution of rainfall on August 26, 1999 where rainfall intensity was measured at104 mm over a six-hour period. The second simulation involved an examination of different types of storms and specifying the drainage capability of the storm sewer network to discharge the runoff. Sheng and Wilson [13] compared the runoff patterns of two types of land use; a forested and an urban area. The results indicated that in urban areas, 90\% of rainfall is lost as run off while only $25 \%$ is lost in forested areas. This clearly shows the negative effect of urbanization increasing the probability of the flooding. Beling et al. [14] calibrated the physical parameters of four sub-catchment areas in Brazil using SWMM. Calibrations were carried out on a number of rainy events (4 to 12), the number depending on the data provided for each sub-catchment. The effects of the physical parameters on the calibration depend on the nature of the sub-catchment but the dominant physical parameters were impervious percent, the width and Manning's roughness coefficient of the sub-catchment.

A comparison has been done between vertical and horizontal discharge in anisotropic soils by using EnDrainWin and WellDrain software's. The results presented that for the same condition, horizontal drainage systems due to the higher spacing between drains were superior to vertical drainage systems. However, a vertical drainage system due to the poorer changes is suitable for situation that soil hydraulic conductivity was probable to change [15].

Jiang et al. [16] used SWMM to forecast flooding in China, one of the countries with the highest rates of urbanization. The simulation used rain data over 1, 2, 5, 10 and 20-year periods, the results indicating that the network only satisfies the design requirements over a 1-year return period and that the network will be hydraulically flooded at other return periods. A framework for predicting future short duration rainfall intensity was developed by Jung et al. [17] who examined the effects of climate change on urban runoff in the Gunja Drainage Basin. The results included a framework proposed to provide a review of stormwater runoff to determine capacity when taking climate change into consideration.

The studies introduced above indicate that the SWMM model is an effective tool able to simulate urban flooding and produce realistic results. Therefore, in the current study, the SWMM has been chosen to simulate urban flooding in storm drainage networks in an area which has been exposed to very high rain intensity in recent years due to climate change. It aims to evaluate and analyze the performance of the storm drainage system under actual hourly rainfall to forecast flooding under different rainfall intensities. The results will help decision makers to develop plans to mitigate urban flooding.

The previous literature reviews climate change knowledge for the study area in the Middle East. This body of knowledge however, is insufficient in comparison with the importance of the impact of climate change both in the present and for the future. In consequence, this study attempts to fill the gap in knowledge and to establish the effect of this global phenomenon for drainage systems in Al-Eskari, and to present appropriate management models for decision makers.

\section{The Study Area}

Geographically, the study area (Al-Eskari quarter) is located to the north of the center of Karbala province, Iraq, between latitudes $32^{\circ} 39^{\prime} 18^{\prime \prime} \mathrm{N}-32^{\circ} 38^{\prime} 42^{\prime \prime} \mathrm{N}$, and longitudes $43^{\circ} 09^{\prime} 06^{\prime \prime} \mathrm{E}-$ $43^{\circ} 57^{\prime} 54^{\prime \prime} \mathrm{E}$, as shown in Fig. 1. It is a flat surface with low slopes and sandy, clay soil. Regional elevations range from 34 $\mathrm{m}$ to $41 \mathrm{~m}$ above sea level. The total area is approximately 1.1 $\mathrm{km}^{2}$, of which $0.372 \mathrm{~km}^{2}$ is pervious (34\% of the total area) with $0.728 \mathrm{~km}^{2}$ impervious (66\% of the total area) including $0.062 \mathrm{~km}^{2}$ of paved roads. The impervious area can be classified as roofs, roads and sidewalks, the pervious classified as gardens and unpaved roads. Dependent on land use and the slope of the area, the quarter is divided into 104 sub-catchment area. All the sub-catchments are directly linked to the storm drainage system. The climate in the study area is desert weather with an extremely hot, long and dry summer from May to October and a short, cold, rainy winter from November to April. The average temperature in winter is $8^{\circ} \mathrm{C}$ reaching $48^{\circ} \mathrm{C}$ in summer. The total annual rainfall in Karbala is less than $92 \mathrm{~mm}$ [18]. The Al-Eskari quarter is only serviced by a storm drainage network, an illegal sewage connection linked to this network. The study area suffers from flooding during the rainy season.

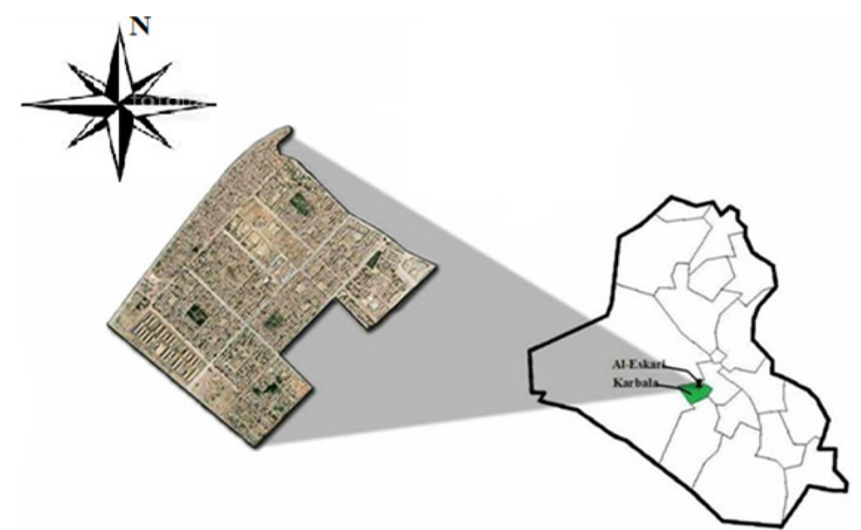

Fig. 1. Geographical location of the study area relative to Iraqi map. 


\section{Methodology}

Hydrology process simulation models attempt to explain the hydrological processes that occur in the real world. They also aim to clarify the hydraulic performance of drainage networks. The models used to generate the rainfall-runoff process, from simple to complex, are divided into three categories; empirical, conceptual and physical [19].

\subsection{Description the Simulation Model}

The SWMM is a dynamic, numerical, conceptual rainfall-runoff model developed by the U.S. Environmental Protection Agency [EPA] [10]. It has the ability to simulate and analyze the quantity and quality of runoff in urban areas based on single or continuous rainfall events. The rainfall-runoff model depends on the physical parameters of the sub-catchment as inserted by the modeler. These parameters include the percentage of impervious materials, width of sub-catchment area, Manning's roughness coefficients overland, infiltration loss, topography, land use type, moisture conditions, rainfall intensity, pervious and impervious areas, depth of depression storage and the capacity of the drainage system. In this study, using Green and Ampt's [20] method of estimate infiltration, SWMM categorized the sub-catchment area as a nonlinear reservoir, the flow route in the subcatchment area defined by using the continuity of mass equation [19]:

$$
\frac{d V}{d t}=\frac{d\left[A^{*} d\right]}{d t} A^{*} I e-Q
$$

The value of $Q$ estimates from the equation below:

$$
Q=\frac{W^{*}\left(d-d_{p}\right)^{\frac{5}{3}} * s^{0.5}}{n}
$$

where: $\left[\frac{d V}{d t}=\frac{d\left[A^{*} d\right]}{d t}\right]$ is the change of volume stored over the sub-catchment over time, $V=\left[A^{*} d\right]$ the volume of water on the sub-catchment $\left[\mathrm{m}^{3}\right], A$ the sub-catchment area $\left[\mathrm{m}^{2}\right]$, and $[d]$ the water depth on the sub-catchment (depth of storage in the reservoir) [m], Ie rainfall excess (rainfall intensity minus evaporation and infiltration rates $[\mathrm{m} / \mathrm{s}]),\left[A^{*} I e\right]$ the precipitation excess from the sub-catchment, $[Q]$ the runoff flow rate from the sub-catchment $\left[\mathrm{m}^{3} / \mathrm{s}\right.$ ] and account depend on Manning [Eq. (2)], $W$ the width of the sub-catchment [m], $d p$ the depth of the depression storage [m], $S$ the slope sub-catchment and $n$ the overland Manning roughness coefficient. The flow routing in pipes and other facilities use an explicit numerical solution (Saint-Venant equations) represented by two partial differential equations [21]. Firstly, the momentum equation is defined as:

$$
\frac{1}{a} \frac{\partial q}{\partial t}+\frac{1}{a} \frac{\partial}{\partial x}\left[\frac{q^{2}}{a}\right]+g \frac{\partial y}{\partial x}-g\left[S_{o}-S_{f}\right]=0
$$

Second, the continuity equation is defined by:

$$
\frac{\partial a}{\partial t}+\frac{\partial q}{\partial x}=0
$$

where: $q$ is the flow rate of the pipes $\left[\mathrm{m}^{3} / \mathrm{s}\right], g$ the acceleration due to gravity $\left[9.8\left(\mathrm{~m} / \mathrm{s}^{2}\right)\right], y$ the depth of flow $[\mathrm{m}], S_{o}$ the bed slope $[\mathrm{m} / \mathrm{m}], S_{f}$ the friction slope $[\mathrm{m} / \mathrm{m}], a$ the cross-sectional area of the pipe $\left[\mathrm{m}^{2}\right], t$ the time $[\mathrm{s}]$ and $x$ the distance along the channel $[\mathrm{m}]$.

\subsection{Building the Model}

Nine years (2008 to 2016) of hourly rainfall data was simulated to analysis the storm drainage network in the study area. The precipitation data was provided by Al-Razaza's meteorology station located at $43^{\circ} 97^{\prime} \mathrm{E}$ and $32^{\circ} 55^{\prime} \mathrm{N}$. The Al-Eskari quarter was divided into 104 sub-catchments with areas ranging from 2,000 to $44,500 \mathrm{~m}^{2}$ as shown in Fig. 2. Geographic Information System [GIS 10.3] software was used to display the study area by digital aerial imaging. GIS provides information on the spatial distribution of the storm drainage system e.g. location, depth and type of manhole, diameter, roughness, length and slope of pipes and area of sub-catchment. The 238 manholes in the study area, shown in Fig. 3, are made of concrete with depths ranging from $1 \mathrm{~m}$ to $3.82 \mathrm{~m}$. The pipe diameters range from $315 \mathrm{~mm}$ to $600 \mathrm{~mm}$ and are made of UPVC material.

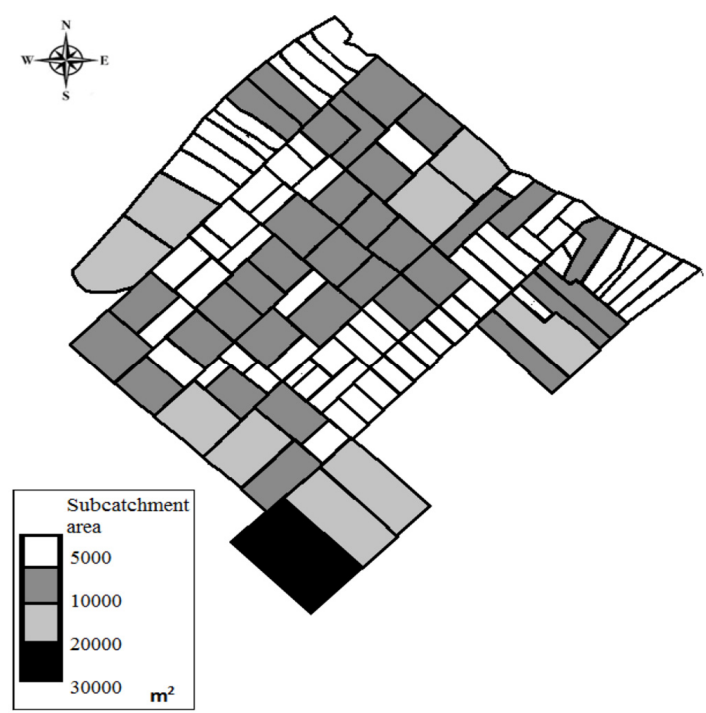

Fig. 2. The division(subcatchment area) of the study area.

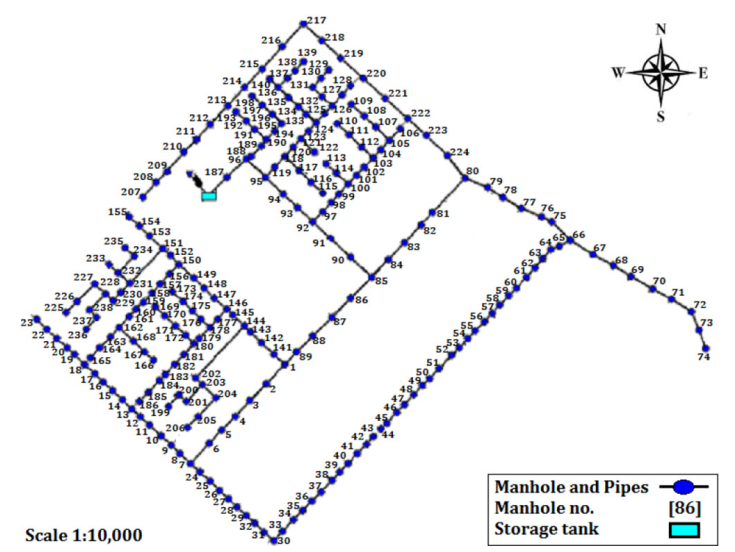

Fig. 3. The storm drainage network of Al-Eskari quarter, Karbala, Iraq. 
Table 1. The Sewage Variation Pattern [24]

\begin{tabular}{cc}
\hline \multicolumn{2}{c}{ Daily pattern } \\
\hline Sun & 1.02 \\
Mon & 1 \\
Tue & 0.99 \\
Wed & 0.95 \\
Thu & 0.94 \\
Fri & 1.01 \\
Sat & 1.1 \\
\hline
\end{tabular}

\begin{tabular}{cc}
\hline \multicolumn{2}{c}{ Monthly pattern } \\
\hline Jan & 1 \\
Feb & 1 \\
Mar & 1 \\
Apr & 1 \\
May & 1 \\
Jun & 1 \\
Jul & 1 \\
Aug & 1 \\
Sep & 1 \\
Oct & 1 \\
Nov & 1 \\
Dec & 1 \\
\hline
\end{tabular}

\begin{tabular}{cccc}
\hline \multicolumn{5}{c}{ Hourly pattern } \\
\hline AM 12:00:00 & 0.9 & PM 12:00:00 & 1.17 \\
AM 01:00:00 & 0.82 & PM 01:00:00 & 1.17 \\
AM 02:00:00 & 0.7 & PM 02:00:00 & 1.13 \\
AM 03:00:00 & 0.64 & PM 03:00:00 & 1.1 \\
AM 04:00:00 & 0.6 & PM 04:00:00 & 1.07 \\
AM 05:00:00 & 0.63 & PM 05:00:00 & 1.08 \\
AM 06:00:00 & 0.75 & PM 06:00:00 & 1.1 \\
AM 07:00:00 & 0.91 & PM 07:00:00 & 1.12 \\
AM 08:00:00 & 1.06 & PM 08:00:00 & 1.12 \\
AM 09:00:00 & 1.18 & PM 09:00:00 & 1.15 \\
AM 10:00:00 & 1.23 & PM 10:00:00 & 1.11 \\
AM 11:00:00 & 1.22 & PM 11:00:00 & 1.01 \\
\hline
\end{tabular}
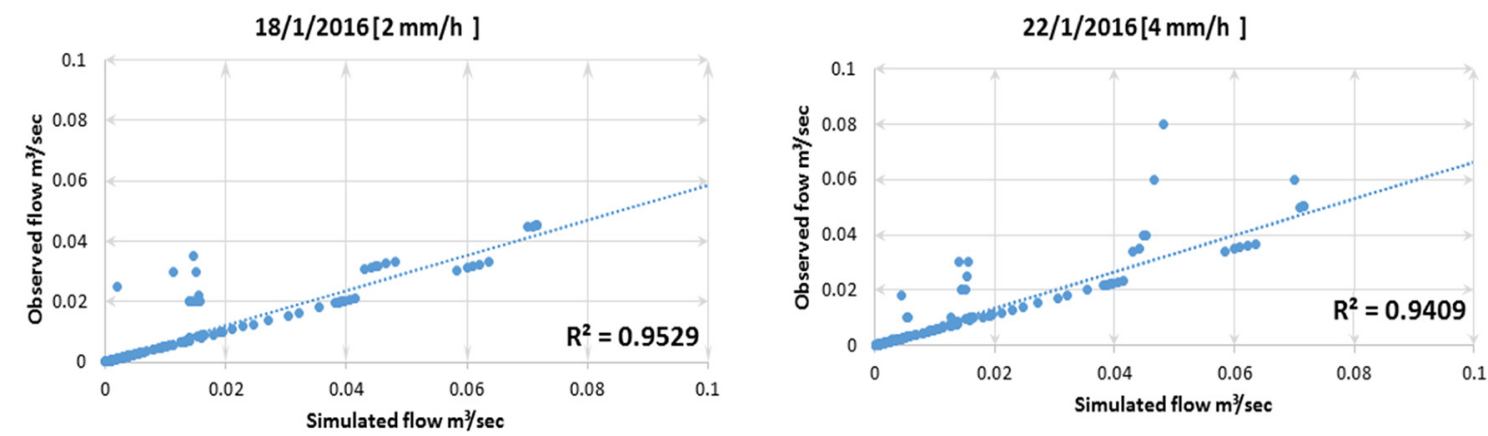

Fig. 4. The calibration result for the simulate model in SWMM.

\subsection{Sewage Quantity}

Because sewage discharge is connected to the storm network in the AL-Eskari quarter, it needs to be included. According to Iraqi Planning Ministry report [22], the water consumption per capita in 2014 in Karbala was about $422 \mathrm{~L} / \mathrm{d}$ per capita. The estimate average sewage for each manhole is as follows [23]:

$$
Q_{a v g}=0.8 * P^{*} G
$$

where: $Q_{\text {avg }}$ is the average sewage discharge $[\mathrm{L} / \mathrm{d}], P$ the population[thousand] and $G$ the water consumption per capita [L/d]. The percent of sewage per capita from water consumption ranges from 70 to $130 \%$ [23]. In Iraq overall, the percent of sewage was approximately $80 \%$. The SWMM requires a time pattern for hourly, daily or monthly variations in sewage. Choi [24] has supplied a time pattern for dry weather flow as shown in Table 1. This variation is suitable for the resident area as recommended by the author.

\section{Results and Discussion}

In order to evaluate the performance of the storm drainage system in the study area, three methods have been used: Calibration of the simulation model for the storm network in Al-Eskari quarter;

analysis of the extent of the urban flooding caused by climate change due to global warming, and evaluation of the effect of quantities of sewage draining through the storm network.

\subsection{Model Calibration}

The calibration of the simulation model was conducted by a manual trial and error method to reduce the difference between the simulation and observation results. The observation data was the total discharge in each manhole during two rainfall events. The first event was in 18/01/2016 where a rainfall intensity of $2 \mathrm{~mm} / \mathrm{h}$ was recorded. The second event was in 22/01/2016 with rainfall intensity of $4 \mathrm{~mm} / \mathrm{h}$. The parameter which had the biggest effect on the calibration results were impervious factor percentage, the width and Manning's roughness coefficient of the sub-catchments these in agreement with [14].

In order to check the validity of all parameters in the model and the estimation of model parameters, cross validation was carried out on the data as shown in Table 2. The cross validation results show that the mean errors (ME) for the two events are very close to zero at 0.0068 and 0.0032 , respectively. The mean square error (MSE) is very low compared to the variance of the observed data for both events. The coefficient of determination $\left[\mathrm{R}^{2}\right]$ for the first rainfall event was 0.95 and 0.94 for the second as shown in Fig. 4. These cross validation results show that the chosen models and their parameters are adequate. 
Table 2. Fitted Parameters (Cross-validation) of Models

\begin{tabular}{|c|c|c|c|}
\hline \multirow{2}{*}{ No. } & \multirow{2}{*}{ Parameters } & \multicolumn{2}{|c|}{ Event } \\
\hline & & 18/1/2016 & $22 / 1 / 2016$ \\
\hline 1. & $\mathrm{ME}$ & 0.0068 & 0.0032 \\
\hline 2. & MSE & 0.0609 & 0.0417 \\
\hline 3. & $\mathrm{R}^{2}$ & 0.952 & 0.940 \\
\hline
\end{tabular}

\subsection{The Effect of Climate Change}

The storm drainage network in the Al-Eskari quarter had been designed for a rainfall intensity of $9.6 \mathrm{~mm} / \mathrm{h}$ and duration of 60 min, representing a 2-year return period. However, the study area has been exposed to the impacts of climate change. There has been a noticeable increase in rainfall intensity, especially after 2012, as shown in Fig. 5. In 2013, rainfall intensity reached 11.3, 17.5, 17, 15.8 and $17.8 \mathrm{~mm} / \mathrm{h}$ on 19/11/2013, 21/11/2013, 29/11/2013, 1/12/2013 and 7/12/2013, respectively. In 2015 and 2016, the maximum rainfall intensity was $33.54 \mathrm{~mm} / \mathrm{h}$ on $11 / 5 / 2015$ and $24.5 \mathrm{~mm} / \mathrm{h}$ on $28 / 3 / 2016$, all of which are above the design intensity of the sewer system which is $9.6 \mathrm{~mm} / \mathrm{h}$.

Due to this increase in rainfall, the study area has become more prone to flooding. The flooding discharge of the manholes is divided into five stages. Stage 1 , no flooding ranging from 0 to $0.001 \mathrm{~m}^{3} / \mathrm{s}$; stage 2 , very light flooding, ranging from greater than 0.001 to $0.01 \mathrm{~m}^{3} / \mathrm{s}$; stage 3 , medium flooding, ranging from greater than 0.01 to $0.02 \mathrm{~m}^{3} / \mathrm{s}$; stage 4 , high flooding, ranging from greater than 0.02 to $0.04 \mathrm{~m}^{3} / \mathrm{s}$ and stage 5 , very high flooding, greater than $0.04 \mathrm{~m}^{3} / \mathrm{s}$. The flooding area, the total area of open space and roads, has been classified depending on the manhole linked to it. The behavior of the storm network under a rainfall storm in 30/12/2008, is illustrated in Fig. 6. 61\% of the manholes had no flooding (stage 1) and $39 \%$ had very light flooding [stage 2] at the peak of the storm. The flooding was continuous for half an hour. Therefore, the behavior of the manholes is considered good, meeting the design requirements.

Fig. 7 shows the storm drainage network under a rainfall intensity of $17 \mathrm{~mm} / \mathrm{h}$, representative of approximately 1.77 times its design intensity. The flooding of the manhole is divided into three stages, where $44 \%$ had a high flooding discharge (stage 3), $27 \%$ had medium flooding discharge and $29 \%$ had light flooding discharge. The duration of the flooding was $27 \mathrm{~h}$.

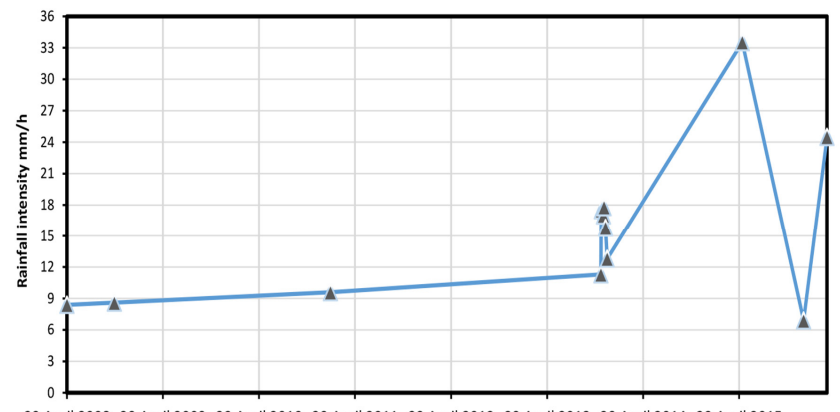

29 April 200829 April 200929 April 201029 April 201129 April 201229 April 201329 April 201429 April 2015 Date day / month / year

Fig. 5. The rainfall intensity event during [2008 to 2016] for study area.

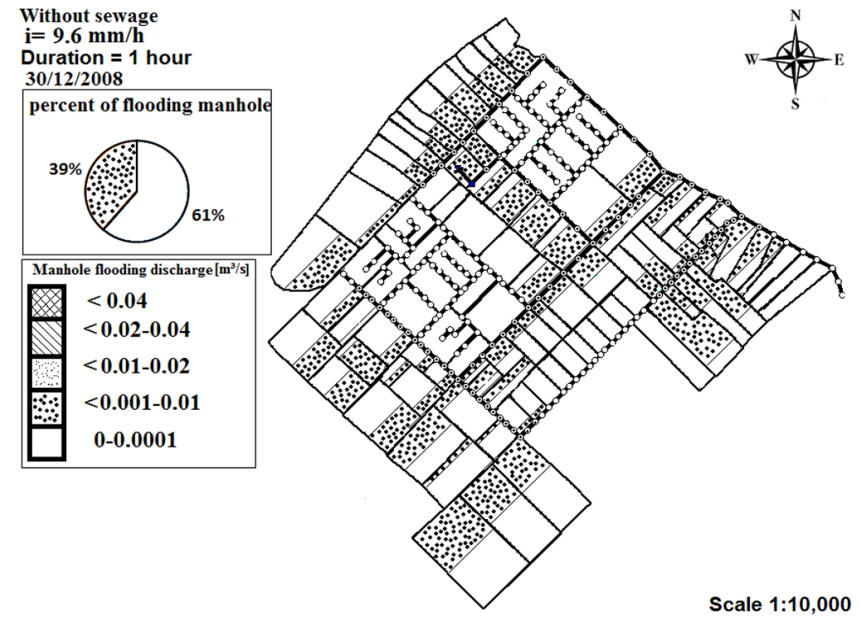

Fig. 6. The flooding manholes under design intensity $[9.6 \mathrm{~mm} / \mathrm{h}]$ at peak time.

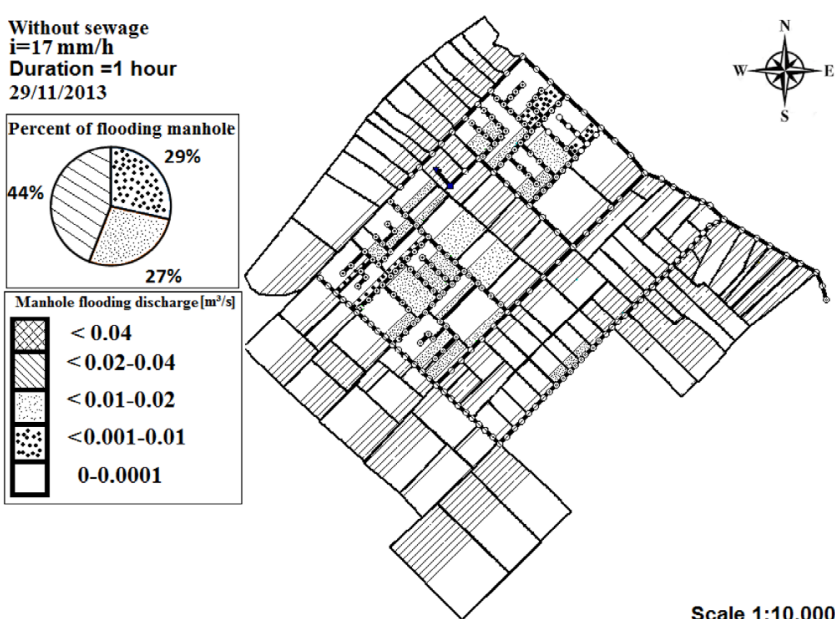

Fig. 7. The flooding manhole under rainfall intensity $[17 \mathrm{~mm} / \mathrm{h}]$ at peak time.

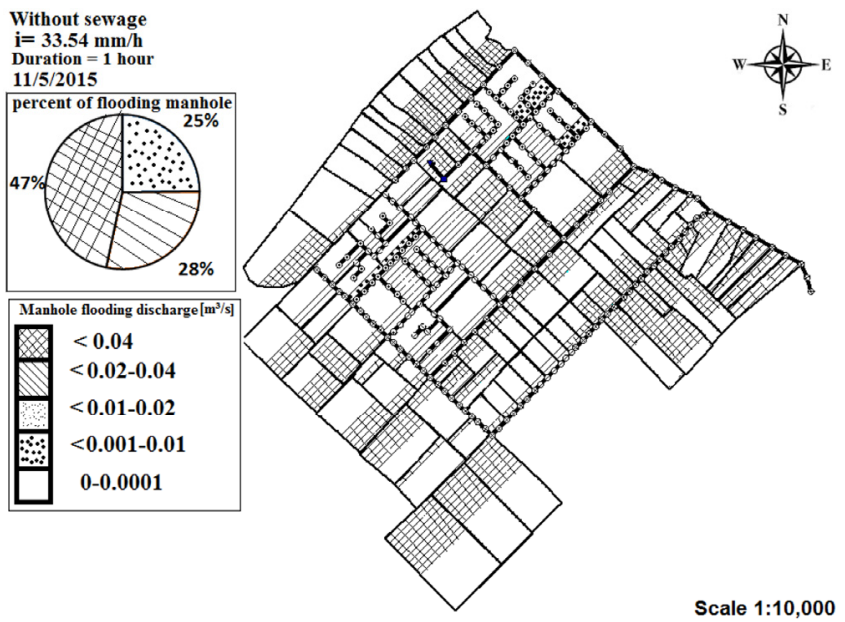

Fig. 8. The flooding manhole under rainfall intensity $[33.5 \mathrm{~mm} / \mathrm{h}]$ at peak time. 
Fig. 8 shows the performance of the storm drainage network under a maximum rainfall intensity of $33.5 \mathrm{~mm} / \mathrm{h}$ on $11 / 05 / 2013$, this representing approximately 3.5 times the design intensity. $47 \%$ of flooding manholes had very high flooding discharge (stage 5), 28\% were in stage 4 (high flooding area) and 25\% flooded at stage 3 (medium flooding). The variation in manhole flooding under maximum rainfall intensity conditions is because of the spatial variation of the manholes; most of the $47 \%$ of the flooded manholes are in the main transporter pipe. These manholes were exposed to a higher load in comparison to other manholes due to the accumulation of sewage and rainfall water from a large sub-catchment. The total duration of the flooding was $43.5 \mathrm{~h}$. Table 3 lists the flooding events with the percent of areas flooded during the period 2008 to 2016 .

\subsection{The Effect of an illegal sewer connection to the Storm Network}

The storm network in the study area is worthy of examination as it carries an illegal amount of sewage. This additional sewage is overloading the drainage capacity of the system and causing clogged pipes. This was the reason behind the flooding of the storm drainage system under extended rainfall.

Fig. 9 shows a comparison in the performance of the system under the two states, with-sewage and without-sewage, under a rainfall intensity lower than the design intensity. It shows that when the system carries sewage, the likelihood of flooding will increase. The percentage of stage 1 (no flooding) in case A was $71 \%$ compared with case B with $60 \%$, indicating an increase in manhole flooding by $11 \%$. The percentage of stage 2 (very light flooding) in case A was $29 \%$ compared to case B which had $40 \%$. The total duration of flooding in case A was half an hour, but case $\mathrm{B}$ was $6 \mathrm{~h}$ due to clogged pipes caused by sewage.

The performance of the storm network in the two cases, with-sewage and without-sewage, under design intensity is illustrated in Fig. 10 which shows that the system was good enough under a design intensity of $9.6 \mathrm{~mm} / \mathrm{h}$, without sewage. The percent of manhole flooding in case A was 39\% at stage 2 (very low flooding)

Table 3. Percent of Flooding Area under the Rainfall Intensities Caused Flooding from 2008 to 2016

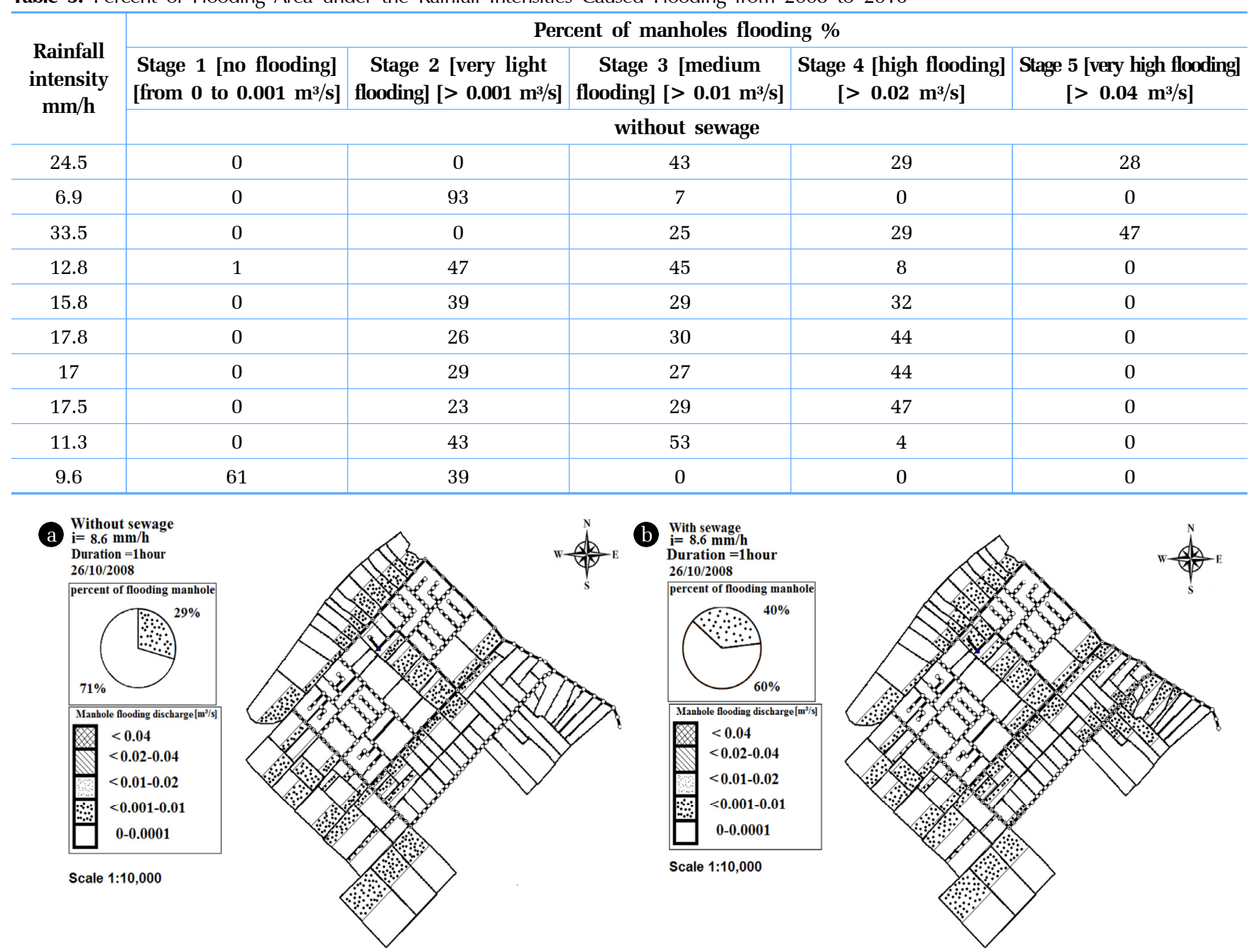

Fig. 9. (a) The system without sewage, (b) The system with sewage [rainfall intensity $8.6 \mathrm{~mm} / \mathrm{h}$ ]. 

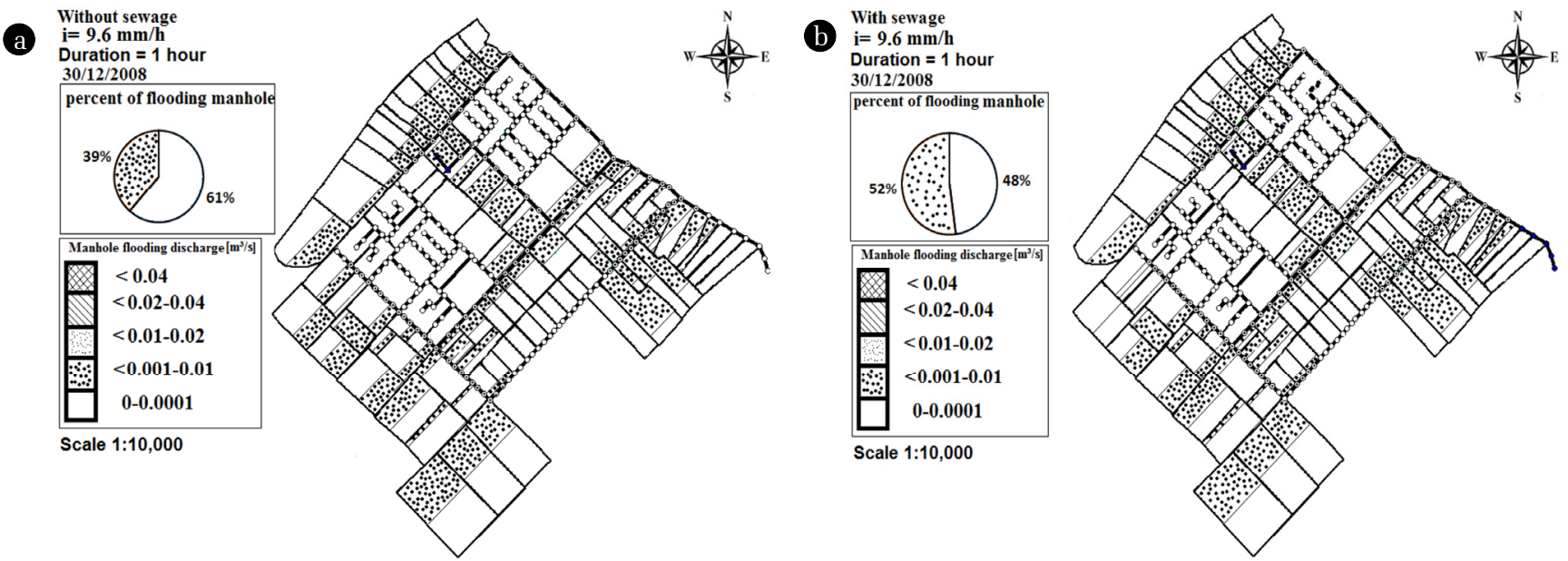

Fig. 10. (a) The system without sewage, (b) The system with sewage [rainfall intensity $9.6 \mathrm{~mm} / \mathrm{h}$ ].
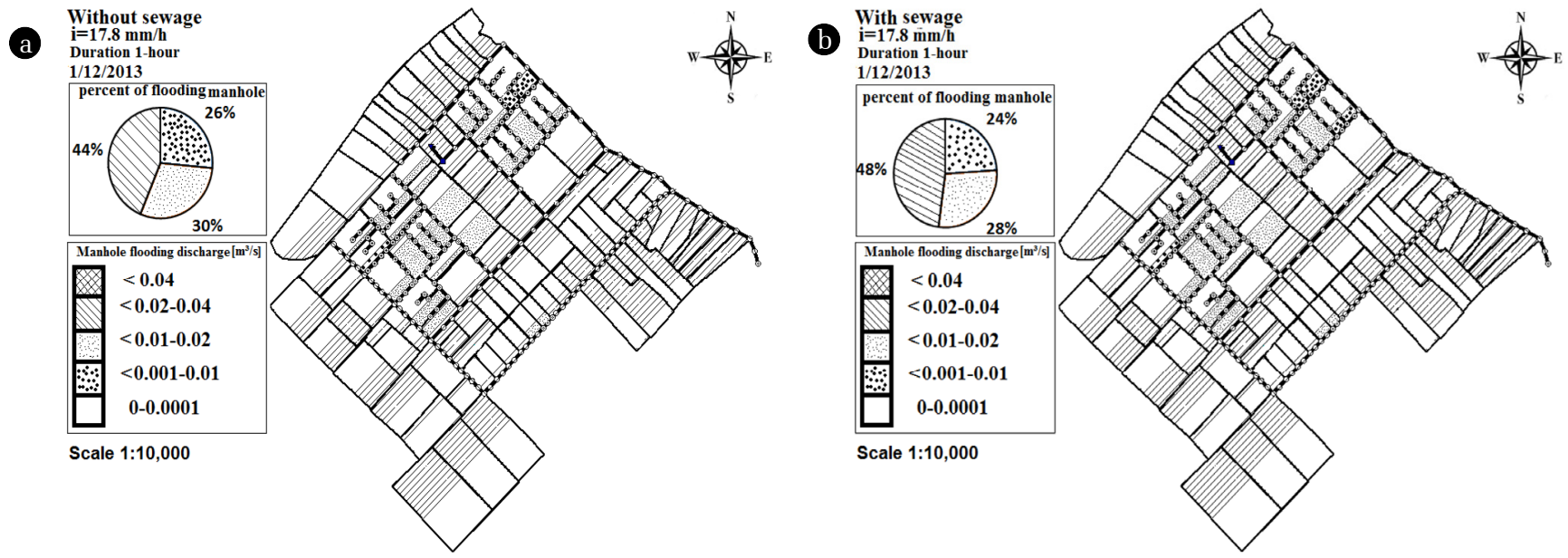

Fig. 11. (a) The system without sewage (b) The system with sewage [rainfall intensity $17.8 \mathrm{~mm} / \mathrm{h}$ ].

while $62 \%$ of manholes had no flooding (stage 1). In the second case (B), the system was affected by the quantity of sewage. The percent of stage 1 flooding (no flooding) decreased from $62 \%$ in case A to $48 \%$ in case B. Stage 2 increased from $39 \%$ in case A to $52 \%$ in case B meaning there was an increase in the number of manholes which flooded. The total duration of flooding in case A was half an hour and in case B, $7 \mathrm{~h}$.

Fig. 11 details the performance of the storm network in both cases, with-sewage and without sewage, under a rainfall intensity higher than the design intensity by 1.7 times. From this figure, the percentage of flooding manholes in case A and B was $26 \%$ and $24 \%$ for stage 2 , respectively, $30 \%$ and $28 \%$ for stage 3 (medium flooding) with $44 \%$ and $48 \%$ at stage 4 (high flooding), respectively. The total duration of flooding in case A was $23 \mathrm{~h}$ while case $\mathrm{B}$ flooded for $52.5 \mathrm{~h}$. The substantial difference in the duration of flooding between the two cases was due to clogged pipes.

\section{Conclusions}

In this study, the aim was to evaluate the performance of a storm drainage network subject to the impact of unplanned climate change, to show the effect of changes in sewage discharge which exceed the design discharge capacity. The SWMM model was used to evaluate the storm drainage system in the Al-Eskari quarter, Karbala, Iraq as a case study to address the aim of the study. The system had been designed for a 2-year return period, with a rainfall intensity of $9.6 \mathrm{~mm} / \mathrm{h}$, for a duration of $60 \mathrm{~min}$. The results showed a deficit in the network's ability to cope with an increased risk of flooding due to climate change in the region, indicating the need to redesign several conduits to improve their reliability. The system's design intensity was suitable when there was no sewage. The quantities of sewage which are currently loading the system have decreased the discharge capacity of the system. It has left sedimentation on the walls of the pipes creating clogging which has increased the duration of flooding. In general, flooding duration was approximately twice as long in comparison to no sewage scenarios.

The results of this study provide an evaluation of the storm drainage system in the study area, which can constitute technical support for decision makers who need to provide plans to improve the control and management of flooding. The study also shows 
the behavior of the system under different rainfall intensities and the expected flooding discharge for the flooding areas. SWMM played a key role in the simulation of urban flooding within the study area, providing results which are in agreement with observations therefore appropriate for use in the estimation of urban flooding.

This work can be extended to other regions who face similar conditions and difficulties, particularly in the Middle East. The study examines the impact of sewage in the storm drainage system, a common problem in the middle east. The results of the research can inform on the extent of damage that sewage may cause on the performance of the storm drainage network and thus be used as evidence for work to upgrade existing networks which are identified as having this problem.

\section{References}

1. Yannopoulos SI, Lyberatos G, Theodossiou N, et al. Evolution of water lifting devices (pumps) over the centuries worldwide. Water 2015;7:5031-5060.

2. Houghton JT, Meira Filho LG, Callander BA, Harris N, Kattenberg A, Maskell K. Climate change 1995: The science of climate change. Contribution of Working Group 1 to the Second Assessment Report of the Intergovernmental Panel on Climate Change. Cambridge, UK: Cambridge University Press; 1996.

3. Valipour M, Sefidkouhi MAG, Raeini M. Selecting the best model to estimate potential evapotranspiration with respect to climate change and magnitudes of extreme events. Agr. Water Manage. 2017;180:50-60.

4. Valipour M. How much meteorological information is necessary to achieve reliable accuracy for rainfall estimations? Agriculture 2016;6:53.

5. Viero DP, Valipour M. Modeling anisotropy in free-surface overland and shallow inundation flows. Adv. Water Resour. 2017;104:1-14.

6. Valipour M. Future of agricultural water management in Africa. Arch. Agron. Soil Sci. 2015;61:907-927.

7. Valipour M. Variations of land use and irrigation for next decades under different scenarios. IRRIGA 2016;1:262-288.

8. Metcalf and Eddy Inc. Storm water management model. Environmental Protection Agency. Washington D.C.; 1971. p. 353.

9. Terstriep ML, Stall JB. The Illinois urban drainage area simulator, ILLUDAS. No. 58. Urbana: Illinois State Water Survey; 1974.

10. Lindberg RL, Negishi M. Alteration of mouse cytochrome
P450coh substrate specificity by mutation of a single amino-acid residue. Nature 1989;22:632-634.

11. Hsu MH, Chen SH, Chang TJ. Inundation simulation for urban drainage basin with storm sewer system. J. Hydrol. 2000;30:21-37.

12. Sands RJ, Chang CC, McDonald JM. Storm water management study after flooding of the South Bronx, NYC, New York. Global Solutions for Urban Drainage; 2002. p. 1-9.

13. Sheng J, Wilson JP. Watershed urbanization and changing flood behavior across the Los Angeles metropolitan region. Nat. Hazards 2009;48:41-57.

14. Beling FA, Garcia JI, Paiva EM, Bastos GA, Paiva JB. Analysis of the SWMM model parameters for runoff evaluation in periurban basins from southern Brazil. In: 12th International Conference on Urban Drainage; 11-16 September 2011; Porto Alegre/Brazil. p. 11-16.

15. Valipour M. A comparison between horizontal and vertical drainage systems (include pipe drainage, open ditch drainage, and pumped wells) in anisotropic soils. IOSR J. Mech. Civil Eng. 2012;4:7-12.

16. Jiang L, Chen YA, Wang HU. Urban flood simulation based on the SWMM model. P. Int. Assoc. Hydrol. Sci. 2015;368:186-191.

17. Jung M, Kim H, Mallari KJ, Pak G, Yoon J. Analysis of effects of climate change on runoff in an urban drainage system: A case study from Seoul, Korea. Water Sci. Technol. 2015;71:653-660.

18. Agricultural meteorology Iraqi network [Internet]. c2015. Available from: http://agromet.gov.iq/index.php?name=News \&file $=$ article\&sid $=185$.

19. Wong TS, Koh XC. Which model type is best for deterministic rainfall-runoff modelling? In: Water Resources Research Progress. New York: Nova Science Publishers; 2008. p. 241-260.

20. Rawls WJ, Brakensiek DL, Miller N. Green-ampt infiltration parameters from soils data. J. Hydrol. Eng. 1983;109:62-70.

21. Pitt R, Lilburn M, Nix S, et al. Guidance manual for integrated wet weather flow (WWF) collection and treatment systems for newly urbanized areas (New WWF Systems). Current and Future Design Practices. 1999 Dec.

22. Iraqi Planning Ministry. Central statistical organization-enviromantal report [Internet]. c2014. Available from: http://www. economy.gov.ae/StatisticsReportsEn/Statistical Report 2014 4th Issue.pdf.

23. Steel EW, McGhee TJ. Water supply and sewage. McGraw-Hill; 1979.

24. Choi NJ. Understanding sewer infiltration and inflow using impulse response functions derived from physics-based models [dissertation]. Urbana-Champaign: Univ. of Illinois; 2016. 